Revista Iberoamericana, Vol. LXXVII, Núm. 235, Abril-Junio 2011, 347-359

\title{
APARIENCIA Y RAZÓN DE UNA POÉTICA ${ }^{1}$
}

POR

NANCy MOREJÓN

Más que apariencia y razón de ser de una poética, ésta será una suerte de historia contada del nacimiento de algunos de mis poemas. $\mathrm{Y}$ es en ese elemental sentido que intentaré volver sobre lo que muchos llaman poética. No me importa tanto esta palabra: poética, pues llama al orden de la academia y destierra toda necesidad de expresión espontánea. Aunque fue muy útil en la antigüedad, hoy no deja de ostentar pretensiones de todo tipo. Por eso es que si hablo de poética es sólo para nombrar un conjunto de versos capaces de traer aquí, ahora, una estampa cordial del trabajo literario que se fundamenta a través de una poesía cuya apariencia no responde siempre a su razón, y viceversa. Tampoco pensé en rastrear definiciones. En el terreno de la poesía intentarlo es caer en arenas inciertas. Vine al Puerto de Santa María con la ilusión de usar su atmósfera como surtidor capaz de establecer una poética de la relación literaria.

Traigo, pues, mucha arena real, mucha ola, mucha franqueza y esa necesidad, todavía joven, de aprender proponiendo; de mostrar a la vez dudas y contradicciones. Hay una apariencia dócil en los poemas que he escogido para leerles. Hay una razón escondida en cada uno de ellos. Apariencia y razón se confrontan y se complementan. Lo importante es la existencia misma del poema más allá de la voluntad de mi escritura o, incluso, de mis presupuestos. Debo confesar (por ello) mi pavor por las nomenclaturas, mi pasión por la independencia diversa ante el papel en blanco cuya presencia respeto y necesito porque me adentra en mis versos virtuales en donde me doy a la aventura permanente en el trasfondo de unas aguas incógnitas, siempre incógnitas, a veces turbias, a veces transparentes, aunque todas en remolino constante.

He tratado en todo momento de llevar a esa página en blanco la transcripción de esa aventura, de ese viaje en donde muchas cosas aparentan la razón de su contrario. No puedo afirmar que haya sido totalmente fiel; pero he intentado, al menos, trasladar

1 Originalmente este texto fue la introducción a una lectura comentada de poemas en el marco de un Encuentro de Poetas Cubanos y Catalanes como homenaje al poeta Rafael Alberti, auspiciado por la Fundación que lleva su nombre y realizada en su sede del Puerto de Santa María, Bahía de Cádiz (España, 1996). (N. del E.) 
mi verdad sin importarme la forma, entendida la forma como un absoluto. Me he valido de formas variadas pero lo que importa es su verdad y, por supuesto, la mía.

Los primeros poemas que escribí aparentaban una existencia verbal contenida, de forma ajena a un conocimiento tradicionalista de mi entorno social. Incapacitada para comunicar algunas razones de mi angustia adolescente, creé una relación verbal con mis sentimientos. Algún tiempo después aquella incapacidad se permutó en el espejo familiar de un discurso poético frecuentado hasta el delirio por los que fuimos jóvenes durante los años sesenta. La convulsión revolucionaria a la que habíamos asistido, en la que participábamos también, nos puso entre las manos confrontaciones filosóficas que recayeron en ese espejo de la familia cubana, tan proveedor de conciencia memoriosa, alabada en nuestros días por críticos de indudable prestigio como el poeta uruguayo Mario Benedetti (Uruguay, 1920-2009).

Decía Virigina Woolf que detrás de toda escritora ronda el fantasma de su madre. Mi espejo familiar refractó la imagen de mi madre en múltiples textos. Con uno de ellos, el que prefiero, quisiera comenzar esta lectura: ${ }^{2}$

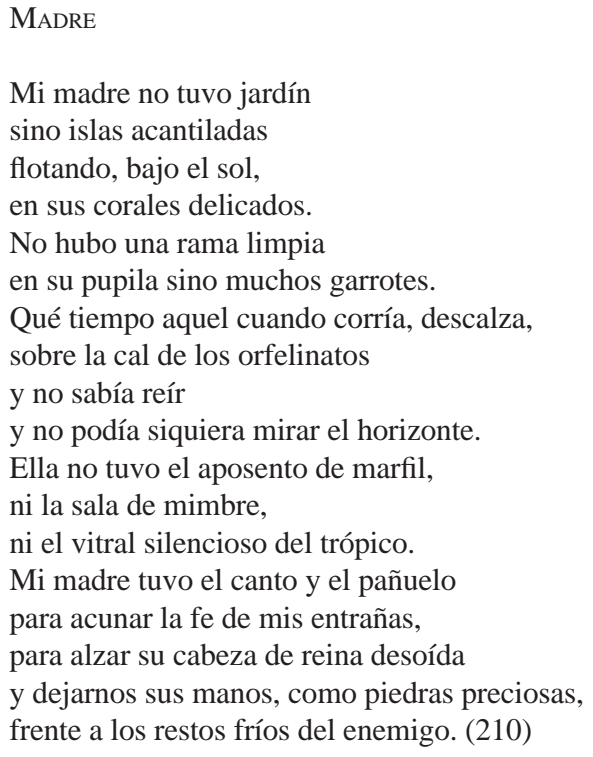

2 Los poemas de Nancy Morejón citados en el presente texto pertenecen al volumen Looking Within / Mirar adentro: Selected Poems/ Poemas escogidos, 1954-2000. Edición bilingüe, editada, anotada y con una Introducción de Juanamaría Cordones-Cook. Heather Rosario Sievert, Kathleen Weaver, Mirta Quintanales, Gabriel Abudu, David Frye y Nancy Abraham Hall, trads. Detroit: Wayne State UP, Colección African-American Life Series, 2003. (N. del E.)

ISSN 0034-9631 (Impreso) 
Espero que hayan apreciado, más allá del espejo familiar aludido, un cierto rumor de palabras, una intención de encontrar un lenguaje que, en aquellos años, nos parecía nuevo. Naturalmente, no eran nada nuevos ni su tema, ni su fondo, ni su ropaje. Otras voces de la poesía cubana habían atravesado los mismos caminos. Pasado el tiempo, veo con más claridad que lo legítimo de aquel interés en sumergirnos en semejante espejo era la valoración y, por consiguiente, la inserción del habla, digamos cotidiana, en la filosofía del poema. Ya para entonces era un acontecimiento intelectual el acercamiento a libros tan sustanciales a la modernidad del siglo como lo fueron Trilce, del peruano César Vallejo (Perú, 1892-París, 1938) y La tierra baldía, del norteamericano T.S. Eliot (Saint Louis, Missouri, 1888-1965) aparecidos ambos, sintomáticamente, en 1922. Las vanguardias comenzaban a hacernos transitar por campos minados de audacia, desgarramiento y premoniciones. Agradezco a ese instante mi aprecio por una poética que se alimenta, vive y se relaciona con el lenguaje hablado. Por mi cuenta y riesgo, me incliné más a trasplantar el lenguaje de la conversación, no así el lenguaje de los libros coloquiales que amaba, como, por ejemplo, En la calzada de Jesús del Monte. A la sombra de los tranvías, bajo el curso infinito de los astros, más allá de los inmóviles portales y las cascadas de columnas, alentaba el silencioso espacio que Eliseo Diego nos regalara en su único gesto posible: el de la belleza cierta sobre la pátina de un pasado que se vuelve posible a su vez.

Luego de tanta lluvia citadina, traté de escribir versos tratando de importar a su naturaleza el modo de hablar de los hombres y mujeres que poblaban los barrios de extramuros. Así se revelaría una de las modalidades que más han permanecido junto a mi gusto literario. Sin embargo, guardé para algún sentimiento patriótico el lirismo que ya había degustado, muy posteriormente, en los poetas románticos cubanos del siglo XIX, en particular de aquellos que nacieron o habitaron junto a las márgenes del río San Juan o del Yumurí, ambos en la provincia de Matanzas.

Veamos este poema que se titula:

LA CLARIDAD

A la manera de un poeta romántico... Para Roberto Fernández Retamar

Cántame, pájaro que vuelas

sobre el espacio austral que desconozco. Húndete en mi sed de persona y pósate en los dedos que conforman mi mano. Iremos a la floresta, después que la lluvia

Revista Iberoamericana, Vol. LXXVII, Núm. 235, Abril-Junio 2011, $347-359$
ISSN 2154-4794 (Electrónico) 


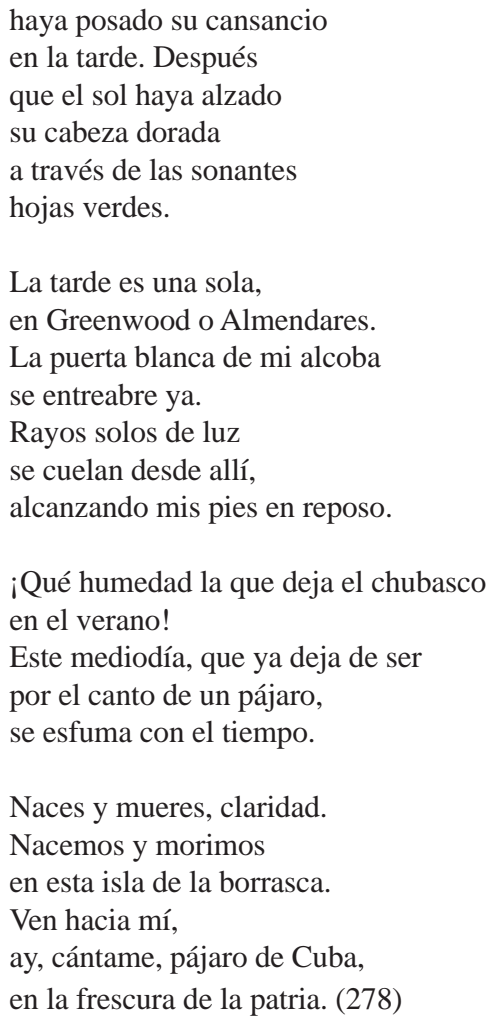

Casi desde el primer siglo, o mucho antes, data este asunto de querer explicar la poesía.

Ahora mismo se abren infinitas posibilidades.

He transitado muchos caminos para llegar a su espiral inalcanzable. Y en situaciones como ésta recuerdo las ideas de Federico García Lorca. Para él, escribir poesía era como penetrar en una selva, de noche, a cazar animales preciosos que no son otra cosa sino las palabras. $\mathrm{Y}$ aunque el poeta no debe dejarse encantar por falsos atractivos es innegable que la poesía, o al menos una parte considerable de su ejercicio, radica en el disfrute de la palabra, nunca desprovista de sus significados más primarios y hermosos.

El territorio ilimitado de la imagen es también imaginación acompañada de lo que conocemos desde la antigüedad como imago. Ambas pueden ser encontradas y, de hecho, se encuentran en cuanta acción humana tiene lugar sobre el planeta y sus alrededores. La posibilidad de un maremoto; del asalto a un cielo compartido; el alumbramiento de una criatura o el sencillo acto de encender una fogata terminándose el día. Entro a un

Revista Iberoamericana, Vol. LXXVII, Núm. 235, Abril-Junio 2011, $347-359$
ISSN 0034-9631 (Impreso) 
cine. Contemplo un girasol y ya nace el poema en medio de la Isla más hermosa que ojos humanos seguirán viendo.

He sido un ave rara y he jugado con las palabras con el fin de expresarlo todo y para no expresar nada. Me he sentido libre y así me he dejado llevar por la palabra misma que proviniese de ese largo rectángulo recorrido lentamente por el caracol de José Lezama Lima, o de la incorporación de una sensualidad visionaria en donde vocales y consonantes se echaron a la mar sólo por el gusto de ir bogando y de refractar en un eco distante las coordenadas de eros y tanatos.

El poeta primaveral Emilio Ballagas me concedió alguna que otra transparencia para escribir algunos poemas orientados hacia esa cuerda suya.

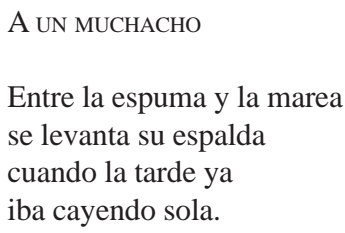

Tuve sus ojos negros, como hierbas, entre las conchas brunas del Pacífico.

Tuve sus labios finos

como una sal hervida en las arenas.

Tuve, en fin, su barbilla de incienso bajo el sol.

Un muchacho del mundo sobre mí y los cantares de la Biblia modelaron sus piernas, sus tobillos y las uvas del sexo y los himnos pluviales que nacen de su boca envolviéndonos sí como a dos nautas enlazados al velamen incierto del amor.

Entre sus brazos, vivo.

Entre sus brazos duros quise morir como un ave mojada. (150)

$\begin{array}{llllll}\text { Revista Iberoamericana, Vol. LXXVII, Núm. 235, } & \text { Abril-Junio 2011, } & \text { 347-359 } \\ \text { ISSN 0034-9631 (Impreso) }\end{array}$ 
EL TAMBOR

Mi cuerpo convoca la llama.

Mi cuerpo convoca los humos.

Mi cuerpo en el desastre

como un pájaro blando.

Mi cuerpo como islas.

Mi cuerpo junto a las catedrales.

Mi cuerpo en la coral.

Aires los de mi bruma.

Fuego sobre mis aguas.

Aguas irreversibles

en los azules de la tierra.

Mi cuerpo en plenilunio.

Mi cuerpo como las codornices.

Mi cuerpo en una pluma.

Mi cuerpo al sacrificio.

Mi cuerpo en la penumbra.

Mi cuerpo en claridad.

Mi cuerpo ingrávido en la luz

vuestra, libre, en el arco. (156)

Durante mi adolescencia tronaban los poetas contra las formas métricas y hasta hubo enemigos encarnizados del soneto. Tiempo después otros poetas consideraban obligatorias las formas métricas y hasta hubo fanáticos de la rima. No creo en la destrucción del lenguaje ni en la de sus formas. Los poemas que escucharán a continuación son ricos en la arbitrariedad de los temas elegidos así como en la diversidad de las formas al uso.

He escrito sonetos, claro; y versos libres y alguna experimentación en busca de un arte poética viva en su transculturación de almas. En definitiva, como señalara Gerardo

ISSN 0034-9631 (Impreso) 
Diego, que como sabemos fuera alguna vez detractor de la vuelta a la estrofa, "todo es retórica y el huir de ella una manera de retórica negativa, mil veces más peligrosa”. ${ }^{3}$

No por azar he traído a estos encuentros mi adolescente reacción ante "el influjo mimético”, es decir, ante el hecho de que la poesía de Rubén Darío desató en su momento una avalancha de seguidores cuyos versos fundaron estereotipos edulcorados gracias, tal vez, a la equivocada recepción que tuvieron sus cisnes entre los bardos provincianos de Hispanoamérica. En este texto, tradición y ruptura se dan la mano para festejar, con profunda admiración, la presencia del genio dariano, liberador de la palabra, entre los más jóvenes.

COMO ANTAÑo

Podríamos sentarnos, como antaño,

a leer el último libro del escritor famoso.

Preferimos el río, la presa, el pájaro,

la cuenca del corazón abierta

para la segadora.

Oh qué humo bendito del futuro

se esfuma entre las manos de los dos. (300)

Alfombra

\section{Para Lourdes Casal}

La idea del poema

entra por la ventana,

perfumada quizás, sin avisarme.

¿Logré acaso engañar

tanto anhelo extraviado...?

Es como si una alfombra,

como si alguien me pusiera

a los pies una alfombra

y firme ya pudiera emprender

limpio vuelo, con la benevolencia yo

de aquel lector cuyo sueño anidaba

la lectura de Boti...

No puedo...

Oh sueño firme,

3 Citado por Rafael Alberti. La arboleda perdida (Memorias). Segunda parte. Barcelona, Seix Barral, 1987.

$\begin{array}{llllll}\text { Revista Iberoamericana, Vol. LXXVII, Núm. 235, } & \text { Abril-Junio 2011, } & \text { 347-359 } \\ \text { ISSN 0034-9631 (Impreso) }\end{array}$ 


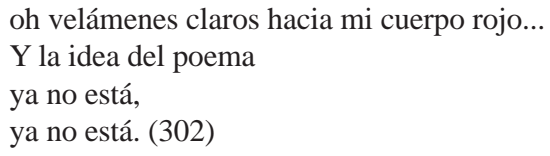

El drama de Calibán, tan cierto en la historia y en la existencia de nuestras "islas dolorosas”, tocó a nuestras puertas.

La poesía de Nicolás Guillén-que expresa lo cubano en esa combustión irreversible de elementos afrohispánicos- me ha brindado todo un cuerpo mitológico de imágenes, inherentes a la ecología de las Antillas. El trópico no se avergüenza de su condición sino que revive con necesaria y sugestiva teluricidad. Jamás encontré en su discurso nada externo o fácil sino esencial. Y ese discurso, a su vez, respiraba un inconmensurable amor a la lengua española que en él -como en mí- es una patria. Sin dejarse adormecer por la cadencia de las hamacas o el simple vuelo de un pájaro campestre, su amor al mar y a la tierra como signos fijos de una sensibilidad antillana muy particular lo conducen a cantarlos como ejes centrales de desastres y hecatombes de carácter universal como lo han sido la trata y la esclavitud. Nuestro mar es un mar de historias amargas, de migraciones incesantes. Nicolás Guillén supo enseñarme esa porción de tristeza que emanaba de buena parte de su obra: "una tristeza ancestral” como precisara Don Ezequiel Martínez Estrada. ${ }^{4}$ De ese “polvo de oro” que desde 1930 había reconocido el poeta guantanamero Regino Boti, ${ }^{5}$ nacieron estos cuatro poemas:

Mirar ADENTRO

Del siglo dieciséis data mi pena

y apenas lo sabía

porque aquel ruiseñor

siempre canta en mi pena. (160)

Mujer NEGRA

Todavía huelo la espuma del mar que me hicieron atravesar.

La noche, no puedo recordarla.

Ni el mismo océano podría recordarla.

Pero no olvido al primer alcatraz que divisé.

Altas, las nubes, como inocentes testigos presenciales.

Acaso no he olvidado ni mi costa perdida, ni mi lengua ancestral.

4 Martínez Estrada, Ezequiel. La poesía afrocubana de Nicolás Guillén. La Habana: Unión, 1967. 73.

5 Ver Boti, Regino. "El verdadero son”. Recopilación de textos sobre Nicolás Guillén. Selección y prólogo de Nancy Morejón. La Habana: Casa de las Américas, 1974. 247-49.

$\begin{array}{llllll} & \text { Revista Iberoamericana, Vol. } & \text { LXXVII, Núm. } & \text { 235, } & \text { Abril-Junio 2011, } & \text { 347-359 } \\ \text { ISSN 0034-9631 (Impreso) }\end{array}$ 
Me dejaron aquí y aquí he vivido.

Y porque trabajé como una bestia, aquí volví a nacer.

A cuanta epopeya mandinga intenté recurrir.

Me rebelé.

Su Merced me compró en una plaza.

Bordé la casaca de Su Merced y un hijo macho le parí.

Mi hijo no tuvo nombre.

Y Su Merced, murió a manos de un impecable lord inglés.

Anduve.

Ésta es la tierra donde padecí bocabajos y azotes.

Bogué a lo largo de todos sus ríos.

Bajo su sol sembré, recolecté y las cosechas no comí.

Por casa tuve un barracón.

Yo misma traje piedras para edificarlo,

pero canté al natural compás de los pájaros nacionales.

Me sublevé.

En esta misma tierra toqué la sangre húmeda y los huesos podridos de muchos otros, traídos a ella, o no, igual que yo.

Ya nunca más imaginé el camino a Guinea.

¿Era a Guinea? ¿A Benín? ¿Era a Madagascar? ¿O a Cabo Verde?

Trabajé mucho más.

Fundé mejor mi canto milenario y mi esperanza.

Aquí construí mi mundo.

Me fui al monte.

Mi real independencia fue el palenque

y cabalgué entre las tropas de Maceo.

Sólo un siglo más tarde, junto a mis descendientes, desde una azul montaña,

bajé de la Sierra

Revista Iberoamericana, Vol. LXXVII, Núm. 235, Abril-Junio 2011, $347-359$
ISSN 2154-4794 (Electrónico) 
para acabar con capitales y usureros,

con generales y burgueses.

Ahora soy: sólo hoy tenemos y creamos.

Nada nos es ajeno.

Nuestra la tierra.

Nuestros el mar y el cielo.

Nuestras la magia y la quimera.

Iguales míos, aquí los veo bailar

alrededor del árbol que plantamos para el comunismo.

Su pródiga madera ya resuena. (200-2)

Амо А МІ Амо

Amo a mi amo.

Recojo leña para encender su fuego cotidiano.

Amo sus ojos claros.

Mansa cual un cordero

esparzo gotas de miel por sus orejas.

Amo sus manos

que me depositaron sobre un lecho de hierbas:

Mi amo muerde y subyuga.

Me cuenta historias sigilosas mientras

abanico todo su cuerpo cundido de llagas y balazos,

de días de sol y guerra de rapiña.

Amo sus pies que piratearon y rodaron

por tierras ajenas.

Los froto con los polvos más finos

que encontré, una mañana,

saliendo de la vega.

Tañó la vihuela y de su garganta salían

coplas sonoras, como nacidas de la garganta de Manrique.

Yo quería haber oído una marímbula sonar.

Amo su boca roja, fina,

desde donde van saliendo palabras

que no alcanzo a descifrar

todavía. Mi lengua para él ya no es la suya.

Y la seda del tiempo hecha trizas.

Oyendo hablar a los viejos guardieros, supe

que mi amor

de latigazos en las calderas del ingenio,

como si fueran un infierno, el de aquel Señor Dios

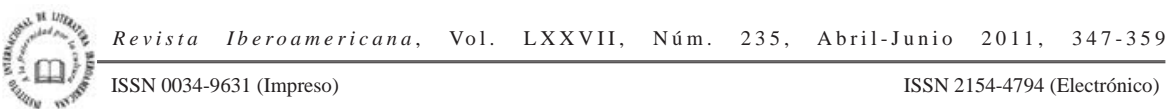


de quien me hablaba sin cesar.

¿Qué me dirá?

¿Por qué vivo en la morada ideal para un murciélago?

¿Por qué le sirvo?

¿Adónde va en su espléndido coche

tirado por caballos más felices que yo?

Mi amor es como la maleza que cubre la dotación, única posesión inexpugnable mía.

\section{Maldigo}

esta bata de muselina que me ha impuesto; estos encajes vanos que despiadado me endilgó; estos quehaceres para mí en el atardecer sin girasoles; esta lengua abigarradamente hostil que no mastico; estos senos de piedra que no pueden siquiera amamantarlo;

este vientre rajado por su látigo inmemorial; este maldito corazón.

Amo a mi amo pero todas las noches, cuando atravieso la vereda florida hacia el cañaveral donde a hurtadillas hemos hecho el amor, me veo cuchillo en mano, desollándole como a una res sin culpa.

Ensordecedores toques de tambor ya no me dejan oír ni sus quebrantos, ni sus quejas.

Las campanas me llaman... (196-98)

Persona

¿Cuál de estas mujeres soy yo?

¿O no soy yo la que está hablando

tras los barrotes de una ventana sin estilo

que da a la plenitud de todos estos siglos?

¿Acaso seré yo la mujer negra y alta

que corre y casi vuela

y alcanza records astronómicos,

con sus oscuras piernas celestiales

en su espiral de lunas?

¿En cuál músculo suyo se dibuja mi rostro, clavado allí como un endecasílabo importado de un país de nieve prohibida?

Revista Iberoamericana, Vol. LXXVII, Núm. 235, Abril-Junio 2011, 347-359 
Estoy en la ventana

y cruza "la mujer de Antonio";

"la vecinita de enfrente", de una calle sin formas;

"la madre -negra Paula Valdés-."

¿Quién es el señorito que sufraga

sus ropas y sus viandas

y los olores de vetiver ya desprendidos de su andar?

¿Qué permanece en mí de esa mujer?

¿Qué nos une a las dos? ¿Qué nos separa?

¿O seré yo la "vagabunda del alba”,

que alquila taxis en la noche de los jaguares

como una garza tendida en el pavimento

después de haber sido cazada

$$
\begin{aligned}
& \text { y esquilmada } \\
& \text { y revendida }
\end{aligned}
$$

por la Quinta de los Molinos

y los embarcaderos del puerto?

Ellas: ¿quiénes serán? ¿o soy yo misma?

¿Quiénes son éstas que se parecen tanto a mí no sólo por los colores de sus cuerpos

sino por ese humo devastador

que exhala nuestra piel de res marcada

por un extraño fuego que no cesa?

¿Por qué soy yo? ¿Por qué son ellas?

¿Quién es esa mujer

que está en todas nosotras huyendo de nosotras,

huyendo de su enigma y de su largo origen

con una incrédula plegaria entre los labios

o con un himno cantado

después de una batalla siempre renacida?

Todos mis huesos, ¿¿serán míos?

¿de quién serán todos mis huesos?

¿Me los habrán comprado

en aquella plaza remota de Gorée?

¿Toda mi piel será la mía

o me han devuelto a cambio

los huesos y la piel de otra mujer

cuyo vientre ha marcado otro horizonte, otro ser, otras criaturas, otro dios?

Estoy en la ventana.

Yo sé que hay alguien.

Sevista Iberoamericana, Vol. LXXVII, Núm. 235, Abril-Junio 2011, 347-359 


\begin{abstract}
Yo sé que una mujer ostenta mis huesos y mi carne; que me ha buscado en su gastado seno y que me encuentra en la vicisitud y el extravío. La noche está enterrada en nuestra piel. La sabia noche recompone sus huesos y los míos. Un pájaro del cielo ha trocado su luz en nuestros ojos. (204-6)
\end{abstract}

"La poesía”, como quería Cesare Pavese, “es una defensa contra las ofensas de la vida” ${ }^{6}$ Para Rafael Alberti, la fuente de las lágrimas sobre el barranco entre Alfacar y Viznar, está todavía llena de escalofríos. Escribo por necesidad. Escribo para fijar lo perdido. Escribo para relacionarme con los seres humanos pero no sé por qué escribo. Un extraño impulso, un misterio extraño me convocan sin tregua ante la página en blanco. Es como entrar a un remolino, a una espontánea danza. Sólo he tenido una aspiración, la misma aspiración que Ortega y Gasset celebraba a propósito de escribir una nota sobre El pasajero, de José Moreno Villa (Madrid, 1914). Decía Ortega y Gasset: “estas son las primeras palabras de un poeta que aspira a lo sumo a que se puede aspirar en arte: a ser él mismo".

He aspirado tan sólo a ser yo misma.

Puerto de Santa María, marzo de 1996

6 Citado por Carlos Colón Perales. Fellini o lo fingido verdadero. Sevilla: Alfar, 1994. 11.

7 Ortega y Gasset, José. La deshumanización del arte y otros ensayos de estética. Madrid: Alianza, 1987. 153.

ISSN 0034-9631 (Impreso) 
